УДК 556.114:616.71(571.55)

\title{
НОВЫЕ ДАННЫЕ ОБ ЭЛЕМЕНТНОМ СОСТАВЕ ПРИРОДНЫХ ВОД В РАЙОНЕ РАСПРОСТРАНЕНИЯ УРОВСКОЙ (КАШИНА-БЕКА) БОЛЕЗНИ (ЗАБАЙКАЛЬСКИЙ КРАЙ)
}

Замана Леонид Васильевич',

I.v.zamana@mail.ru

Рихванов Леонид Петрович²,

rikhvanov@tpu.ru

Соктоев Булат Ринчинович²,

bulatsoktoev@tpu.ru

Барановская Наталья Владимировна², nata@tpu.ru

Эпова Екатерина Сергеевна',

apikur1@ya.ru

Солодухина Мария Анатольевна',

mabn@ya.ru

Михайлова Лариса Альфредасовна ${ }^{3}$,

mihailova-la@mail.ru

Копылова Юлия Григорьевна²,

kyg@tpu.ru

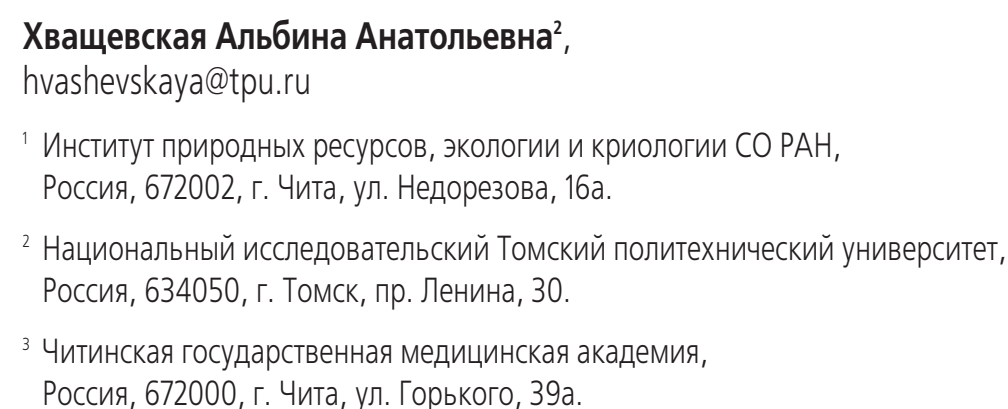

Актуальность. Болезнь Кашина-Бека, или уровская болезнь, известна уже более 160 лет, однако до сих пор не выявлена истинная причина, вызывающая развитие данного заболевания. На данный момент известно более 20 теорий и гипотез, объясняющих причины ее появления, ведущей из которых является биогеохимическая, впервые предложенная А.П. Виноградовым. Согласно данной теории, болезнь Кашина-Бека обусловлена влиянием фактора окружающей среды в виде недостатка или избытка химического элемента/соединений. В связи с этим актуальным является изучение химического состава компонентов природной среды в зоне проявления данной болезни.

Цель исследования: оценка химического состава природных вод, используемых для питьевого водоснабжения, на территории проявления болезни Кашина-Бека в Забайкальском крае.

объекты: подземные и поверхностные воды.

Методы. Гидрогеохимический, элементный состав проб воды определен методом масс-спектрометрии с индуктивно связанной плазмой.

Результаты. Изучено содержание 71 химического элемента, в том числе ранее не рассматриваемых для данной территории, в природных водах. Установлено, что воды, используемые для питьевого водоснабжения, характеризуются низким содержанием кальция, что может являться индикатором неблагополучия территории по этому заболеванию без отягчающего влияния как стронция, так фосфора и марганца. Содержания селена, как и йода, в изученных водах находятся ниже оптимального для питьевого использования уровня, что хорошо согласуется с литературными данными по Китаю, где в районах распространения болезни Кашина-Бека компоненты природной среды (воды, почвы, растительность) обеднены йодом. В данном случае недостаток йода может вызвать развитие эндемического зоба, на фоне которого уровская болезнь проявляется ярче.

\section{Ключевые слова:}

Уровская болезнь, болезнь Кашина-Бека, гидрогеохимия, элементный состав,

подземные и поверхностные воды, кальций, селен, йод. 


\section{Введение}

Вот уже более 160 лет после публикации заметки землемера И.М. Юренского в «Трудах вольного экономического общества» (1849) идут исследования уровской (название дано по месту ее первого выявления - р. Уров) болезни или болезни Кашина-Бека (по фамилиям врачей, впервые изучивших этот недуг - Н.И. Кашина и Е.В. Бека).

Болезнь Кашина-Бека ( уровская» болезнь, «Big Bone Disease») представляет собой общее заболевание с преимущественным поражением костносуставной системы в виде деформирующего хондроостеоартроза (Ф.П. Сергиевский, Н.И. Дамперов, Л.Ф. Кравченко и др.). Этот же диагноз обсуждается и сегодня [1]. Заболевание обычно начинается в период роста организма, развивается постепенно и медленно, протекает преимущественно хронически. В конечном итоге она приводит к нарушению функций опорно-двигательного аппарата и к ограничению трудоспособности.

Ареал распространения данной болезни на территории Забайкальского края охватывает бассейны рр. Уров, Урюмкан, Газимур, Унда, Зола, верховьев рр. Нижняя и Средняя Борзя и ряда других. Судя по схематичной карте (рис. 1), построенной по материалам Н.А. Дамперова [2], очаг болезни достаточно локализован. Согласно тем же материалам, средняя заболеваемость по территории составляла $33 \%$.

На этиологию заболевания за все время исследований высказано более 20 гипотез, которые можно разделить на несколько групп, основные из которых это биогеохимические и микробиологические $[1,3,4]$. Высказываются точки зрения и о полиэтиологичности этого заболевания [5-12]. Начиная с 1940-х гг. ведущей гипотезой является биогеохимическая, впервые предложенная А.П. Виноградовым. Согласно ей, болезнь Кашина-Бека обусловлена особенностями химизма окружающей среды, вследствие которых наблюдается своеобразная реакция организма на избыток или недостаток того или иного химического элемента.

Из биогеохимических взглядов на природу данного заболевания следует отметить следующие гипотезы: 1) Са-Р, высказанную А.П. Виноградовым; 2) $\mathrm{Ca}-\mathrm{Sr}(\mathrm{Ba})$, предложенную В.В. Ковальским; 3) P-Mn, обосновываемую А.В. Вощенко с коллегами. Во всех без исключения случаях природной средой, ответственной за заболеваемость населения, считается питьевая вода, а затем уже все остальные компоненты. Именно с качеством воды связывают заболеваемость местного населения. В ряде исследований фигурируют такие термины, как «здоровая» и «вредная (больная) вода», которые перешли и в научную литературу (А.П. Виноградов, Ф.П. Сергиевский и др.). Неслучайно, что одним из методов борьбы с этим недугом было переселение на «здоровые» воды (Н.И. Кашин и др.). В связи с этим изучению вод было уделено внимание многих исследователей (П.Н. Палей и др.). Одним из последних обобщений результатов гидрогеохимических съёмок, выполненных геологами на территории Забайкальского края при реализации общих и специальных тематических исследо-

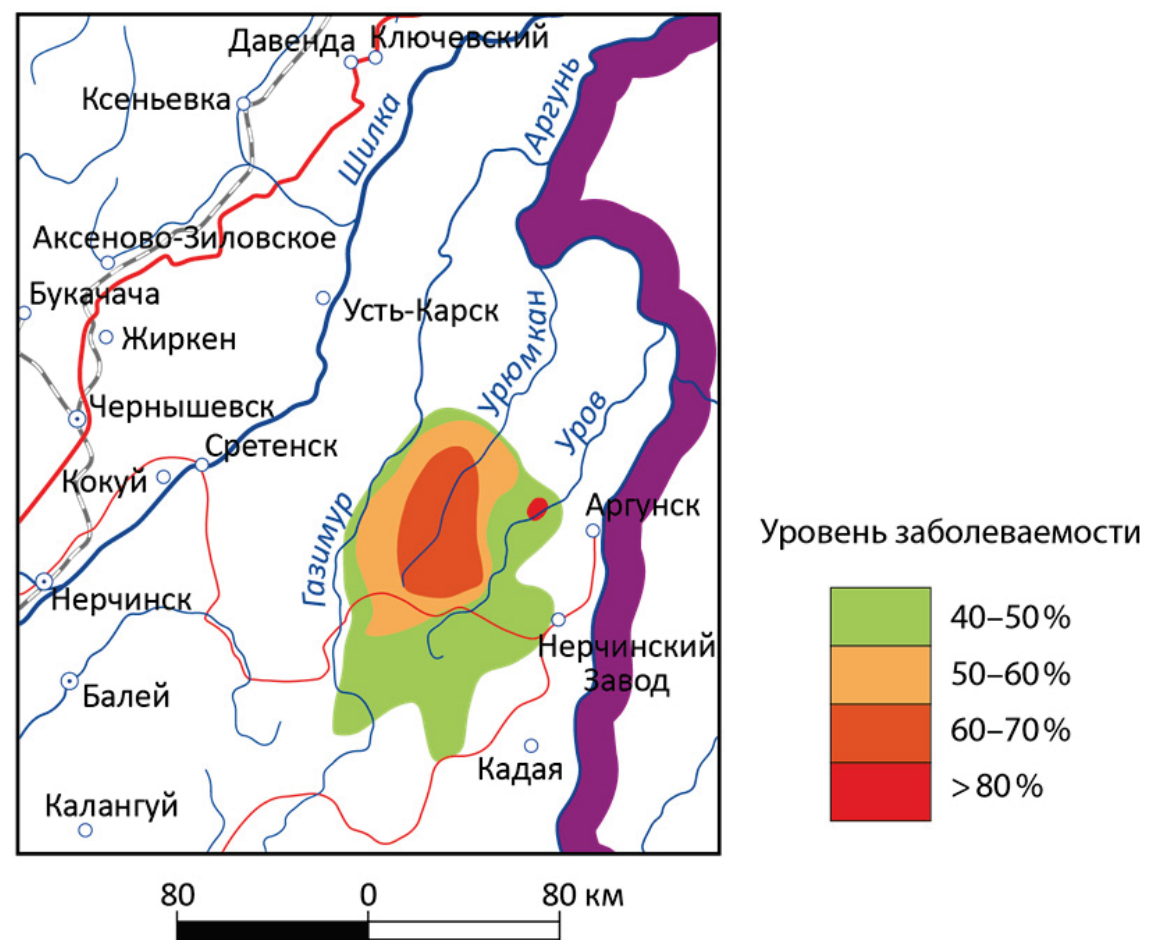

Puс.1. Схематическая карта пространственного распространения болезни Кашина-Бека (основана на материалах карты [2])

Fig.1. Schematic map of Kaschin-Beck disease spatial distribution (based on the map [2]) 
ваний, являются данные, опубликованные Л.В. Заманой [13-16]. С тех пор гидрогеохимические исследования за редким исключением не ведутся, так же как и сама проблема болезни Кашина-Бека по ряду причин, в том числе из-за уменьшения количества больных (А.В. Вощенко и др.), перестала обсуждаться в российской научной литературе.

В свою очередь эта болезнь, как показывает литературный поиск, имеет более широкую распространённость. Наибольшее ее распространение отмечено в Китае, где по различным оценкам около 2,5 миллионов человек подвержены этой болезни и более 30 миллионов проживают в районе ее проявления [17]. Другими регионами, где болезнь распространена, являются Северная Корея и, возможно, некоторые области в Африке [4, 18]. В мировой научной англоязычной литературе болезнь получила свою аббревиатуру (KBD - Kashin-Beck disease, Kaschin-Beck disease), a также еще одну гипотезу, объясняющую этиологию заболевания, Se теория, которая является в настоящее время в Китае доминирующей. Согласно ей, главным фактором развития болезни Кашина-Бека является недостаток данного химического элемента в окружающей среде и его биодоступность [19-26].

Всё это предопределило необходимость вернуться к данной проблеме в России четверть века спустя после закрытия в 1993 г. специализированной Проблемной научно-исследовательской лаборатории (ПНИЛ) по изучению причин, диагностики и методов лечения уровской болезни.

\section{Объекты и методы исследования}

Опробование водных источников было выполнено в сентябре 2017 г. В пункты опробования включены постоянно или временно используемые для питьевого водоснабжения источники как подземных, так и поверхностных вод (табл. 1). В региональном плане все они относятся к территории распространения уровской эндемии, но характеризуются различными уровнями ее проявления.

Село Уровские Ключи входило в число исследованных А.П. Виноградовым пунктов [27] и относилось им, по его терминологии, к «здоровым». Село Тайна было взято по причине его включения в исследования А.В. Вощенко с коллегами [28, 29]: по состоянию на 1988 г. 30,4 \% жителей было поражено этим заболеванием. Село Калга использовалось нами как условный фон. Были также опробованы минеральные углекислые воды курорта Ямкун, на котором лечились больные уровской болезнью.

Анализ проб воды выполнен в проблемной научно-исследовательской лаборатории гидрогеохимии научно-образовательного центра «Вода» Национального исследовательского Томского политехнического университета (аттестат аккредитации № POCC RU.0001.511901 от 09.09.2013 г.). Элементный состав проб определен методом массспектрометрии с индуктивно-связанной плазмой (ICP-MS) на масс-спектрометре NexION 300D coгласно методике HCAM 480X (аналитик Ю.Н. Буткевич).

Пробы для анализа предварительно не фильтровались. Из компонентов анионного состава в ре-

Таблица 1. Места отбора водных проб

Table 1. Water sampling sites

\begin{tabular}{|c|c|c|c|c|}
\hline \multirow{2}{*}{\begin{tabular}{c|} 
Проба \\
Sample
\end{tabular}} & \multirow{2}{*}{$\begin{array}{c}\text { Место отбора } \\
\text { Sampling location }\end{array}$} & \multirow{2}{*}{$\begin{array}{c}\text { Дополнительные сведения } \\
\text { Additional data }\end{array}$} & \multicolumn{2}{|c|}{ Координаты/Coordinates } \\
\hline & & & c.ш./N & в.д./E \\
\hline $\begin{array}{l}\text { 3AБ-1 } \\
\text { ZAB-1 }\end{array}$ & \multirow{2}{*}{$\begin{array}{l}\text { с. Калга } \\
\text { Kalga }\end{array}$} & $\begin{array}{l}\text { гостиница, питьевая } \\
\text { hotel, drinking water }\end{array}$ & $50^{\circ} 55^{\prime} 30,5^{\prime \prime}$ & $118^{\circ} 54^{\prime} 01,3^{\prime \prime}$ \\
\hline \begin{tabular}{|l|} 
ЗАБ-2 \\
ZAB-2
\end{tabular} & & $\begin{array}{c}\text { p. Анчор, мост } \\
\text { Ahchor river, bridge }\end{array}$ & $50^{\circ} 55^{\prime} 26,8^{\prime \prime}$ & $118^{\circ} 53^{\prime} 45,1^{\prime \prime}$ \\
\hline \begin{tabular}{l|} 
3AБ-3 \\
ZAB-3
\end{tabular} & \multirow{4}{*}{$\begin{array}{l}\text { с. Уровские Ключи } \\
\text { Urovskie Klyuchi }\end{array}$} & $\begin{array}{c}\text { p. Уров, мост } \\
\text { Urov river, bridge }\end{array}$ & $51^{\circ} 36^{\prime} 45,4^{\prime \prime}$ & $119^{\circ} 24^{\prime} 27,1^{\prime \prime}$ \\
\hline \begin{tabular}{|l|} 
3AБ-4 \\
ZAB-4
\end{tabular} & & $\begin{array}{l}\text { родник } \\
\text { spring }\end{array}$ & $51^{\circ} 41^{\prime} 37,6^{\prime \prime}$ & $119^{\circ} 27^{\prime} 57,5^{\prime \prime}$ \\
\hline \begin{tabular}{l|} 
3AБ-5 \\
ZAB-5
\end{tabular} & & $\begin{array}{c}\text { р. Уров, в черте села } \\
\text { Urov river, within village boundaries }\end{array}$ & $51^{\circ} 41^{\prime} 33,0^{\prime \prime}$ & $119^{\circ} 27^{\prime} 54,0^{\prime \prime}$ \\
\hline \begin{tabular}{l|} 
3AБ-6 \\
ZAB-6
\end{tabular} & & $\begin{array}{l}\text { ул. Новая, вода привозная, централизованный источник водоснабжения } \\
\text { Novaya street, imported water, centralized source of water supply }\end{array}$ & $51^{\circ} 41^{\prime} 34,4^{\prime \prime}$ & $119^{\circ} 27^{\prime} 48,0^{\prime \prime}$ \\
\hline \begin{tabular}{l|} 
ЗАБ-7 \\
ZAB-7
\end{tabular} & \multirow{3}{*}{$\begin{array}{l}\text { c. Тайна } \\
\text { Taina }\end{array}$} & $\begin{array}{c}\text { ул. Центральная, вода привозная, централизованный источник водоснабжения } \\
\text { Tsentralnaya street, imported water, centralized source of water supply }\end{array}$ & $51^{\circ} 35^{\prime} 12,2^{\prime \prime}$ & $118^{\circ} 27^{\prime} 09,6^{\prime \prime}$ \\
\hline \begin{tabular}{l|} 
ЗАБ-8 \\
ZAB-8
\end{tabular} & & $\begin{array}{l}\text { ул. Центральная, д. 15, скважина глубиной } 4 \text { м } \\
\text { 15, Tsentralnaya street, well depth } 4 \mathrm{~m}\end{array}$ & $51^{\circ} 35^{\prime} 07,3^{\prime \prime}$ & $118^{\circ} 28^{\prime} 20,5^{\prime \prime}$ \\
\hline $\begin{array}{l}\text { 3АБ-9 } \\
\text { ZAB-9 }\end{array}$ & & $\begin{array}{l}\text { p. Тайна, мост } \\
\text { Taina river, bridge }\end{array}$ & $51^{\circ} 35^{\prime} 10,2^{\prime \prime}$ & $118^{\circ} 27^{\prime} 48,4^{\prime \prime}$ \\
\hline \begin{tabular}{l|}
$\mathrm{AAB}-10$ \\
$\mathrm{ZAB}-10$
\end{tabular} & $\begin{array}{l}\text { c. Газимурский Завод } \\
\text { Gazimursky Zavod }\end{array}$ & $\begin{array}{l}\text { p. Газимур, мост } \\
\text { Gazimur river, bridge }\end{array}$ & $51^{\circ} 33^{\prime} 05,8^{\prime \prime}$ & $118^{\circ} 19^{\prime} 49,8^{\prime \prime}$ \\
\hline \begin{tabular}{l|} 
ЗАБ-11 \\
ZAB-11
\end{tabular} & \multirow{2}{*}{$\begin{array}{l}\text { с. Ямкун } \\
\text { Yamkun }\end{array}$} & $\begin{array}{c}\text { курорт, озеро } \\
\text { health resort, lake }\end{array}$ & $51^{\circ} 31^{\prime} 36,3^{\prime \prime}$ & $118^{\circ} 19^{\prime} 57,7^{\prime \prime}$ \\
\hline \begin{tabular}{l|}
$\mathrm{AAB}-12$ \\
$\mathrm{ZAB}-12$
\end{tabular} & & $\begin{array}{l}\text { курорт, ручей, вытекающий из озера } \\
\text { health resort, effluent spring }\end{array}$ & $51^{\circ} 31^{\prime} 35,7^{\prime \prime}$ & $118^{\circ} 19^{\prime} 56,7^{\prime \prime}$ \\
\hline
\end{tabular}


зультатах представлены только данные по сульфатному и хлоридному ионам, но из-за отсутствия этих компонентов в методике анализа полученные значения отнесены аналитиком к полуколичественным. Концентрации гидрокарбонат-иона для определения химического типа и минерализации воды вычислены по разности сумм эквивалентов найденных аналитически катионов и анионов. Разница между ними полностью отнесена на гидрокарбонат-ион. Другие анионы $\left(\mathrm{F}^{-}, \mathrm{NO}_{3}^{-}\right)$обычно содержатся в незначимых для определения типа и минерализации воды количествах, обычно не более $1 \%$-экв. Минерализация воды рассчитана по сумме весовых концентраций катионов и анионов. Наименование химического типа воды дано согласно отраслевому стандарту ОСТ 41-05-263-86 с более $20 \%$-эквивалентов по нарастанию концентраций ионов.

Всего было проанализировано содержание 71 компонента, в том числе редкоземельных элементов, платиноидов и многих других редких элементов, но в большинстве проб их содержание было ниже предела обнаружения. Данная информация показана дальше в обсуждении.

\section{Результаты}

Пересчет результатов анализов по компонентам ионного состава на эквивалентную форму показал, что по анионам суммы эквивалентов не до- стигают и половины сумм по катионам. Поэтому в анионном составе гидрокарбонат-ион по всем пробам стал преобладающим. Расчетные концентрации $\mathrm{HCO}_{3}{ }^{-}$представлены в табл. 2. Для сравнения в таблицу включены данные по тому же роднику в с. Уровские Ключи (проба Ур-31) по результатам опробования от 05.07.1989 г. с аналитическими определениями всех макрокомпонентов. Как видно, наибольшие относительные расхождения концентраций по двум срокам отбора проб приходятся на сульфат- и хлор-ионы, но они могут быть обусловлены не только аналитическими погрешностями, но и режимными колебаниями состава воды. Эти расхождения из-за невысоких концентраций обоих компонентов существенно не влияют ни на величину общей минерализации, ни на определение химического типа воды. Рассчитанное аналогичным образом содержание $\mathrm{HCO}_{3}^{-}$по пробе Ур-31 равно 305,6 мг/дм³ аналитически установленным значением практически в пределах ошибки измерения. Отсюда можно заключить, что вычисленные содержания гидрокарбонат-иона близки к реальным.

По анионному составу изученные воды гидрокарбонатные или сульфатно-гидрокарбонатные (табл. 3), по катионам - кальциевые или щелочноземельные с переменными соотношениями кальция и магния, за исключением пробы ЗАБ-7 с водой чисто натриевого состава.

Таблица 2. Химические характеристики вод в точках опробования

Table 2. Chemical characteristics of water at sampling sites

\begin{tabular}{|c|c|c|c|c|c|c|c|c|c|c|c|}
\hline \multirow{3}{*}{$\begin{array}{c}\text { Проба } \\
\text { Sample }\end{array}$} & \multicolumn{8}{|c|}{ Компоненты ионного состава, мг/дм³ $/$ Components of the ion composition, $\mathrm{mg} / \mathrm{dm}^{3}$} & M & $\mathrm{Sr}$ & $\mathrm{Si}$ \\
\hline & \multirow{2}{*}{$\frac{\mathrm{Ca}^{2+}}{58,35}$} & \multirow{2}{*}{$\begin{array}{l}\mathrm{Mg}^{2+} \\
8,99\end{array}$} & \multirow{2}{*}{$\begin{array}{c}\mathrm{Na}^{+} \\
11,35\end{array}$} & \multirow{2}{*}{$\frac{\mathrm{K}^{+}}{0,85}$} & \multirow{2}{*}{$\begin{array}{l}\mathrm{Fe}^{2+} \\
0,06\end{array}$} & \multirow{2}{*}{$\begin{array}{l}\mathrm{SO}_{4}{ }^{2-} \\
18,17\end{array}$} & \multirow{2}{*}{$\begin{array}{c}\mathrm{Cl}^{-} \\
7,63\end{array}$} & \multirow{2}{*}{$\frac{\mathrm{HCO}_{3}^{-}}{219,0}$} & \multicolumn{3}{|c|}{$\frac{1}{\mathrm{M} \Gamma / \mathrm{AM}^{3} / \mathrm{mg} / \mathrm{dm}^{3}}$} \\
\hline & & & & & & & & & 298,5 & 0,67 & 7,84 \\
\hline $\begin{array}{l}\text { 3АБ-2 } \\
\text { ZAB-2 }\end{array}$ & 43,88 & 6,65 & 7,22 & 1,65 & 0,24 & 12,77 & 4,43 & 164,7 & 224,1 & 0,34 & 7,21 \\
\hline $\begin{array}{l}\text { 3АБ-3 } \\
\text { ZAB-3 }\end{array}$ & 23,06 & 9,74 & 7,64 & 1,11 & 0,38 & 18,89 & 0,52 & 117,7 & 159,6 & 0,22 & 5,35 \\
\hline $\begin{array}{l}\text { 3АБ-4 } \\
\text { ZAB-4 }\end{array}$ & 53,1 & 30,14 & 3,3 & 2,73 & 0,05 & 11,18 & 1,52 & 311,1 & 413,3 & 0,11 & 4,86 \\
\hline $\begin{array}{l}\text { Yp-31 } \\
\text { Ur-31 }\end{array}$ & 57,9 & 30,3 & 3,8 & 1,5 & 0,05 & 25,3 & 2,88 & 300,0 & 423,0 & 0,31 & 5,1 \\
\hline $\begin{array}{l}3 \mathrm{AB}-5 \\
\text { ZAB-5 }\end{array}$ & 23,92 & 11,04 & 6,6 & 1,29 & 0,26 & 17,93 & 0,77 & 125,7 & 187,7 & 0,2 & 5,09 \\
\hline $\begin{array}{l}\text { 3АБ-6 } \\
\text { ZAB-6 }\end{array}$ & 47,93 & 36,92 & 2,5 & 0,86 & 0,79 & 13,59 & 0,34 & 326,4 & 415,4 & 0,1 & 4,65 \\
\hline $\begin{array}{l}\text { 3АБ-7 } \\
\text { ZAB-7 }\end{array}$ & 3,78 & 0,40 & 153,1 & 0,31 & 1,83 & 124,3 & 0,44 & 265,4 & 549,5 & 0,037 & 3,58 \\
\hline $\begin{array}{l}\text { 3АБ-8 } \\
\text { ZAB-8 }\end{array}$ & 74,15 & 56,37 & 5,37 & 1,77 & 2,62 & 37,56 & 1,32 & 485,6 & 664,8 & 0,22 & 8,49 \\
\hline $\begin{array}{l}\text { 3АБ-9 } \\
\text { ZAB-9 }\end{array}$ & 45,72 & 25,26 & 7,31 & 1,63 & 0,28 & 54,67 & 1,29 & 218,4 & 354,6 & 0,38 & 5,28 \\
\hline $\begin{array}{l}\text { 3AБ-10 } \\
\text { ZAB-10 }\end{array}$ & 23,55 & 11,29 & 7,66 & 2,25 & 0,66 & 22,85 & 2,23 & 121,4 & 191,9 & 0,26 & 6,16 \\
\hline $\begin{array}{l}\text { 3AБ-11 } \\
\text { ZAB-11 }\end{array}$ & 202,1 & 175,3 & 12,97 & 4,74 & 1,37 & 66,19 & 1,52 & 1465 & 1929 & 0,98 & 11,61 \\
\hline $\begin{array}{l}\text { 3AБ-12 } \\
\text { ZAB-12 }\end{array}$ & 210,2 & 191,8 & 14,37 & 4,34 & 2,88 & 64,88 & 1,49 & 1582 & 2072 & 1,03 & 11,78 \\
\hline
\end{tabular}

Примечание: $M$ - минерализация.

Note: $M$ - mineralization. 
Таблииа 3. Химический состав и отношения компонентов в водах

Table 3. $\quad$ Chemical composition and ratios of components in the waters

\begin{tabular}{|c|c|c|c|}
\hline $\begin{array}{l}\text { Проба } \\
\text { Sample }\end{array}$ & $\begin{array}{l}\text { Формула химического состава } \\
\text { Chemical composition formula }\end{array}$ & $\mathrm{Ca} / \mathrm{Sr}$ & $\mathrm{Ca} / \mathrm{P}$ \\
\hline \multicolumn{4}{|c|}{ Поверхностные воды/Surface waters } \\
\hline $\begin{array}{l}\text { 3АБ-2 } \\
\text { ZAB-2 }\end{array}$ & $\begin{array}{c}\mathrm{HCO}_{3}{ }^{-} 87,4 \mathrm{SO}_{4}{ }^{2-} 8,7 \mathrm{Cl}^{-} 3,9 \\
\mathrm{Ca}^{2+} 70,6 \mathrm{Mg}^{2+} 17,7 \mathrm{Na}^{+} 10 \mathrm{~K}^{+} 1,3\end{array}$ & 129 & $>627$ \\
\hline $\begin{array}{l}\text { 3AБ-3 } \\
\text { ZAB-3 }\end{array}$ & $\begin{array}{c}\mathrm{HCO}_{3}{ }^{-} 82,8 \mathrm{SO}_{4}{ }^{2-} 16,8 \\
\mathrm{Ca}^{2+} 49,3 \mathrm{Mg}^{2+} 38,4 \mathrm{Na}^{+} 14,2 \mathrm{~K}^{+} 1,3\end{array}$ & 105 & $>329$ \\
\hline $\begin{array}{l}\text { 3AБ-5 } \\
\text { ZAB-5 }\end{array}$ & $\begin{array}{c}\mathrm{HCO}_{3}{ }^{-} 84,1 \mathrm{SO}_{4}{ }^{2-} 15,1 \\
\mathrm{Ca}^{2+} 49 \mathrm{Mg}^{2+} 37,6 \mathrm{Na}^{+} 11,8 \mathrm{~K}^{+} 1,2\end{array}$ & 120 & $>342$ \\
\hline $\begin{array}{l}\text { 3АБ-9 } \\
\text { ZAB-9 }\end{array}$ & $\begin{array}{c}\mathrm{HCO}_{3}^{-} 75,2 \mathrm{SO}_{4}{ }^{2-} 23,9 \\
\mathrm{Ca}^{2+} 48,1 \mathrm{Mg}^{2+} 44,1 \mathrm{Na}^{+} 6,7\end{array}$ & 120 & $>653$ \\
\hline $\begin{array}{l}\text { ЗАБ- } 10 \\
\text { ZAB-10 }\end{array}$ & $\begin{array}{c}\mathrm{HCO}_{3}{ }^{-7} 78,6 \mathrm{SO}_{4}{ }^{2-} 19 \mathrm{Cl}^{-2} 2,4 \\
\mathrm{Mg}^{2+} 47,2 \mathrm{Ca}^{2+} 46,6 \mathrm{Na}^{+} 13 \mathrm{~K}^{+} 2,4\end{array}$ & 91 & $>336$ \\
\hline \multicolumn{4}{|c|}{ Подземные воды/Groundwater } \\
\hline $\begin{array}{l}\text { 3AБ-1 } \\
\text { ZAB-1 }\end{array}$ & $\begin{array}{c}\mathrm{HCO}_{3}^{-} 85,9 \mathrm{SO}_{4}{ }^{2-} 9,1 \mathrm{Cl}^{-} 5 \\
\mathrm{Ca}^{2+} 69,9 \mathrm{Mg}^{2+} 17,9 \mathrm{Na}^{+} 11,7\end{array}$ & 87 & $>833$ \\
\hline $\begin{array}{l}\text { 3AБ-4 } \\
\text { ZAB-4 }\end{array}$ & $\begin{array}{c}\mathrm{HCO}_{3}{ }^{-} 95 \mathrm{SO}_{4}{ }^{2-} 4,3 \\
\mathrm{Ca}^{2+} 49,4 \mathrm{Mg}^{2+} 46,7 \mathrm{Na}^{+} 2,6 \mathrm{~K}^{+} 1,3\end{array}$ & 483 & $>759$ \\
\hline $\begin{array}{l}\text { Yp-31 } \\
\text { Ur-31 }\end{array}$ & $\begin{array}{c}\mathrm{HCO}_{3}{ }^{-} 88,8 \mathrm{SO}_{4}{ }^{2-} 9,6 \mathrm{Cl}^{-1} 1,4 \\
\mathrm{Ca}^{2+} 51,5 \mathrm{Mg}^{2+} 44,8 \mathrm{Na}^{+} 3 \mathrm{~K}^{+} 0,7\end{array}$ & 187 & $>5790$ \\
\hline $\begin{array}{l}\text { 3АБ-6 } \\
\text { ZAB-6 }\end{array}$ & $\begin{array}{c}\mathrm{HCO}_{3}{ }^{-} 94,9 \mathrm{SO}_{4}{ }^{2-}-5 \\
\mathrm{Mg}^{2+} 46,7 \mathrm{Ca}^{2+} 42,6 \mathrm{Na}^{+} 1,9\end{array}$ & 440 & $>685$ \\
\hline $\begin{array}{l}\text { 3АБ-7 } \\
\text { ZAB-7 }\end{array}$ & $\begin{array}{c}\mathrm{HCO}_{3}{ }^{-} 63,6 \mathrm{SO}_{4}{ }^{2-} 37,3 \\
\mathrm{Na}^{+} 95,8 \mathrm{Ca}^{2+} 2,7 \\
\end{array}$ & 102 & $>54$ \\
\hline $\begin{array}{l}\text { 3АБ-8 } \\
\text { ZAB-8 }\end{array}$ & $\begin{array}{c}\mathrm{HCO}_{3}{ }^{-9} 90,7 \mathrm{SO}_{4}{ }^{2-} 8,9 \\
\mathrm{Mg}^{2+} 53,5 \mathrm{Ca}^{2+} 42,2 \mathrm{Na}^{+} 2,6 \mathrm{Fe}^{2+} 1\end{array}$ & 337 & $>1059$ \\
\hline \multicolumn{4}{|c|}{ Курорт «Ямкун»/Health resort «Yamkun» } \\
\hline $\begin{array}{l}\text { ЗАБ-11 } \\
\text { ZAB-11 }\end{array}$ & $\begin{array}{c}\mathrm{HCO}_{3}{ }^{-9} 94,4 \mathrm{SO}_{4}{ }^{2-}-5,4 \\
\mathrm{Mg}^{2+} 57,4 \mathrm{Ca}^{2+} 39,7 \mathrm{Na}^{+} 2,2\end{array}$ & 206 & $>2887$ \\
\hline $\begin{array}{l}\text { ЗАБ-12 } \\
\text { ZAB-12 }\end{array}$ & $\begin{array}{c}\mathrm{HCO}_{3}-95 \mathrm{SO}_{4}^{2-4,9} \\
\mathrm{Mg}^{2+} 58,5 \mathrm{Ca}^{2+} 38,5 \mathrm{Na}^{+} 2,3\end{array}$ & 204 & $>3002$ \\
\hline
\end{tabular}

Согласно полученным данным, содержание $\mathrm{Ca}$ в речных водах изменяется в пределах 23,1-45,7 мг/дм ${ }^{3}$, а минерализация - от 159,6 до 354,6 мг/дм³ . Максимальные значения обоих показателей имеет вода в р. Тайна, что определяется влиянием на гидрохимические характеристики этой реки разработок россыпного и рудного золота в ее бассейне. В подземных водах опробованных источников водоснабжения, исключая привозную воду в с. Тайна, Са установлен в концентрациях 47,9-74,1 мг/дм ${ }^{3}$ при общей минерализации 295,8-694,8 мг/дм ${ }^{3}$ А.П. Виноградов по роднику в с. Уровские Ключи, по-видимому, тому же, что опробован нами, приводит содержание данного химического элемента в воде $5,2 \cdot 10^{-3} \%$ [27], что соответствует 52 мг/дм ${ }^{3}$ и практически равно нашим данным (табл. 2).

Концентрации $\mathrm{Sr}$, как одного из возможных отягчающих факторов уровской болезни по $[27,30]$, в опробованных пресных водах составили 0,037-0,67 мг/дм³ , а содержания Р, избыток которого в кальций-фосфорном балансе является одной из причин заболевания по другой гипотезе [28, 31], во всех пробах оказались ниже предела обнаружения (0,07 мг/дм $)$. Из проанализированного списка 71 химического элемента в поверхностных водах 23 химических элемента (Be, P, Sc, V, Cu, Ga, Ge, $\mathrm{Se}, \mathrm{Br}, \mathrm{Ag}, \mathrm{Cd}, \mathrm{Sn}, \mathrm{Eu}, \mathrm{Tb}, \mathrm{Dy}, \mathrm{Ho}, \mathrm{Er}, \mathrm{Tm}, \mathrm{Yb}, \mathrm{Lu}$, $\mathrm{W}, \mathrm{Re}, \mathrm{Tl})$ характеризуются содержаниями ниже предела обнаружения, в подземных - 28 (Be, P, Sc, Ti, V, Ga, Se, Br, Y, Zr, Ag, Cd, Sn, La, Pr, Nd, Sm, Eu, Gd, Tb, Dy, Ho, Er, Tm, Yb, Lu, Re, Th). Аномальные концентрации имели только Мо $\left(15 \mathrm{м \kappa г} /\right.$ дм $\left.^{3}\right)$ и U $\left(0,019 \mathrm{мг} /\right.$ дм$\left.^{3}\right)$ в водном источнике в с. Калга (табл. 4), что может быть вызвано наличием соответствующей рудной минерализации в 30не влияния водозабора или формирования фильтрационного потока к нему. Содержание других микроэлементов в исследованных водах не превышало фоновых значений, включая $\mathrm{Mn}$, также отнесенный к этиологическим факторам болезни [28, 31]. Содержание $\mathrm{Pb}$, на который, как и на $\mathrm{Mo}$, рекомендовал обратить внимание А.П. Виноградов, только в одном случае (проба ЗАБ-7) достигло 1,2 мкг/дм ${ }^{3}$, что ниже допустимой нормы для питьевых вод $\left(0,03 \mathrm{мг} /\right.$ дм $^{3}$ по СанПиН 2.1.4.10749-01), хотя и самое высокое в выборке. Ве, элемент I класса токсичности, в пресных водах не обнаружен, но в углекислой воде его концентрация выше допустимой $\left(0,0002 \mathrm{мг} /\right.$ дм$\left.^{3}\right)$. Обращает на себя внимание повышенное содержание в водах $\mathrm{Li}$, что и не удивительно для данного региона, обладающего ярко выраженной литиевой спецификой. Лантаноиды выявлены только в речных водах, исключая Се в пробе ЗАБ-7, при этом лишь в р. Газимур кроме La, Се и Nd установлены Pr, Sm и Gd в концентрациях, немногим более предела обнаружения $\left(0,00005 \mathrm{мг} /\right.$ дм$\left.^{3}\right)$. Наличие аналитически улавливаемых концентраций лантаноидов в речных водах связано, очевидно, с переходом их в водную фазу из взвешенных веществ и/или мелкодисперсных донных отложений.

$\mathrm{Se}$ в опробованных водах не обнаружен (менее $0,005 \mathrm{Mr} /$ дм³ $^{3}$ ), что соответствует существующим оценкам территории как селенодефицитной $[32,33]$, и дальнейшее исследование этого компонента потребует использования методики его определения ниже 5 мкг/л. Данные по I, хотя и являются полуколичественными, подтверждают недостаток его в питьевых водах, по всем пробам его содержание не достигает оптимального уровня (>10 мкг/дм ${ }^{3}$ по [34]).

Гидрогеохимические характеристики теплой $\left(22-25^{\circ} \mathrm{C}\right)$ минеральной воды курорта Ямкун мало отличаются от известных ранее. Состав воды гидрокарбонатный кальциево-магниевый, общая минерализация около 2 г/дм ${ }^{3}$. Содержания $\mathrm{Fe}$ и $\mathrm{Si}$ не достигают принятых бальнеологических норм для отнесения к лечебным по этим показателям (10 и 18 мг/дм ${ }^{3}$, соответственно), поэтому вода не соответствует ни дарасунскому, ни кукинскому бальнеологическим типам, выделенным в ГОСТ Р 54316-2011 по углекислым водам Забайкалья. Основным лечебным фактором ее служит углекислота и радон. Но для уровских больных очевидно особое значение высокого содержания Са в воде. Обратим внимание на более высокие показатели минерализации и концентрации ряда элементов в стоке из озера, указывающие на поступление с глубины более богатых ими вод. 


\section{Обсуждение}

Как отмечено выше, по гидрохимическим показателям выделяется используемая для водоснабжения привозная вода в с. Тайна. Наиболее высокое из всех проб содержание $\mathrm{SO}_{4}{ }^{2-}$ в ней, предположительно, можно объяснить влиянием сульфидной минерализации на участке размещения водозаборного сооружения. На это указывает и повышенное содержание Zn, универсального индикатора сульфидного оруденения [35], а также Fe. Ho природа сугубо натриевого состава пресной природной воды неясна. Для вод зоны гипергенеза такой химический состав исключительный. Объяснить его удалением обоих щелочноземельных элементов из воды в результате гидрогенного минералообразования невозможно, поскольку по карбонатам и сульфатам $\mathrm{Ca}$ и $\mathrm{Mg}$ вода не насыщена. Кроме Сa, на эту пробу пришлись и минимальные содержания $\mathrm{Sr}$ и $\mathrm{Si}$, хотя в водах эндемичных местностей, напротив, отмечены повышенные концентрации $\mathrm{Si}[14,15]$. Еще одна особенность этой пробы - максимум по Li (табл. 4).

Наглядно геохимические особенности данной пробы выражены в спектрах, нормированных по концентрациям химических элементов в байкальской воде из [36]. На графике (рис. 2, ЗАБ-7) по шести элементам ( $\mathrm{Mg}, \mathrm{K}, \mathrm{Ca}, \mathrm{Rb}, \mathrm{Sr}, \mathrm{Ba})$ фигуративные точки занимают нижние позиции, по пяти (Li, B, Na, Al, Ni) - верхние и еще по четырем $(\mathrm{Ge}, \mathrm{Ce}, \mathrm{W}, \mathrm{Pb})$ представлены только одной этой пробой. Последнее, но по трем другим элементам $(\mathrm{Ti}, \mathrm{Cr}, \mathrm{Cu})$, наблюдается и по пробе воды из с. Кал- га, аномальной к тому же, как показано выше, по урану и молибдену (рис. 2, ЗАБ-1).

В целом изученные воды, как поверхностные, так и подземные, характеризуются повышенными коэффициентами концентраций относительно байкальской воды. Для большинства определенных методом ICP-MS химических элементов данный показатель больше 1 , достигая максимума для $\mathrm{Fe}$ в поверхностных (>1000) и подземных ( 1000) водах (рис. 2,3$)$. Также для поверхностных вод необходимо отметить концентрирование $\mathrm{Al}, \mathrm{Ti}, \mathrm{Zr}, \mathrm{P} 3 Э$, $\mathrm{Hg}$ более чем в 100 раз в пробе из с. Газимурский Завод (рис. 3, ЗАБ-10).

По содержанию Са $\left(3,8\right.$ мг/дм $\left.{ }^{3}\right)$ привозная вода из с. Тайна, единственная из питьевых, по А.П. Виноградову [27], относится к категории «больных». В «здоровых» родниковых и речных водах по приведенным им данным концентрации Са находились в интервале 30-80 мг/дм³ (пересчитано с содержания в \%), тогда как в «больных» были менее 20 , вплоть до 3 мг/дм³. Сa/Sr отношение, рекомендованное в качестве дополнительного критерия неблагополучия территории по уровской болезни при его значении менее 100 [37], лишь немногим выше (табл. 3) только по причине очень низкого содержания Sr. В работе [27] показано, что это отношение мало отличается по категориям вод - от 63 до 243 в «здоровых», в пределах 62-247 в «больных» водах при содержаниях стронция $0,08-0,54$ и $0,05-0,80$ мг $/$ дм $^{3}$, соответственно. Более того, сам автор работы отметил параллельный рост концентраций $\mathrm{Ca}$ и $\mathrm{Sr}$ и в среднем большее со-

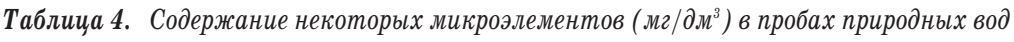

Table 4. Content of several trace elements $\left(\mathrm{mg} / \mathrm{dm}^{3}\right)$ in samples of natural waters

\begin{tabular}{|c|c|c|c|c|c|c|c|c|c|c|c|c|}
\hline Элемент & 3АБ-1 & ЗАБ-2 & ЗАБ-3 & ЗАБ- 4 & $3 \mathrm{AБ}-5$ & 3АБ- 6 & ЗАБ-7 & ЗАБ-8 & ЗАБ- 9 & ЗАБ-10 & ЗАБ-11 & ЗАБ-12 \\
\hline Element & ZAB-1 & $\mathrm{ZAB}-2$ & ZAB-3 & ZAB-4 & ZAB-5 & ZAB-6 & ZAB-7 & ZAB-8 & ZAB-9 & ZAB-10 & ZAB-11 & ZAB-12 \\
\hline $\mathrm{Li}$ & 0,015 & 0,012 & 0,0085 & 0,0068 & 0,0076 & 0,0048 & 0,095 & 0,017 & 0,0067 & 0,0073 & 0,1 & 0,12 \\
\hline $\mathrm{Be}$ & $<0,0001$ & $<0,0001$ & $<0,0001$ & $<0,0001$ & $<0,0001$ & $<0,0001$ & $<0,0001$ & $<0,0001$ & $<0,0001$ & $<0,0001$ & 0,00048 & 0,00053 \\
\hline B & 0,018 & 0,0046 & 0,0054 & 0,0056 & 0,0031 & 0,0042 & 0,049 & 0,013 & 0,018 & 0,0047 & 0,045 & 0,04 \\
\hline $\mathrm{Al}$ & 0,002 & 0,019 & 0,022 & 0,0032 & 0,016 & 0,0071 & 0,043 & 0,0023 & 0,082 & 0,33 & 0,044 & 0,0087 \\
\hline $\mathrm{Cr}$ & $<0,002$ & 0,0024 & $<0,002$ & $<0,002$ & $<0,002$ & $<0,002$ & $<0,002$ & 0,0039 & 0,0032 & 0,0026 & 0,0041 & 0,0076 \\
\hline $\mathrm{Mn}$ & 0,012 & 0,023 & 0,052 & 0,00084 & 0,025 & 0,027 & 0,016 & 0,029 & 0,044 & 0,012 & 0,89 & 1,0 \\
\hline $\mathrm{Co}$ & $<0,0001$ & 0,00015 & 0,00014 & $<0,0001$ & 0,0001 & 0,00051 & 0,00039 & 0,00019 & 0,00032 & 0,00022 & 0,0021 & 0,0046 \\
\hline $\mathrm{Ni}$ & $<0,002$ & 0,0021 & $<0,002$ & $<0,002$ & $<0,002$ & $<0,002$ & 0,0042 & 0,0022 & 0,0028 & $<0,002$ & 0,0038 & 0,0046 \\
\hline $\mathrm{Cu}$ & $<0,002$ & $<0,002$ & $<0,002$ & $<0,002$ & $<0,002$ & $<0,002$ & $<0,002$ & 0,0022 & $<0,002$ & $<0,002$ & 0,0057 & 0,0046 \\
\hline $\mathrm{Zn}$ & 0,0069 & $<0,002$ & $<0,002$ & $<0,002$ & $<0,002$ & 0,0097 & 0,022 & 0,045 & 0,003 & 0,0041 & 0,02 & 0,0046 \\
\hline As & 0,0053 & $<0,002$ & $<0,002$ & 0,0038 & $<0,002$ & $<0,002$ & $<0,002$ & $<0,002$ & 0,0082 & $<0,002$ & 0,026 & 0,058 \\
\hline $\mathrm{Rb}$ & 0,00063 & 0,0011 & 0,0013 & 0,0024 & 0,0014 & 0,00098 & 0,00017 & 0,0026 & 0,0013 & 0,0016 & 0,011 & 0,01 \\
\hline Mo & 0,015 & 0,004 & 0,00081 & 0,00062 & 0,00067 & 0,00047 & 0,00066 & 0,00035 & 0,0026 & 0,00095 & $<0.0002$ & 0,00043 \\
\hline $\mathrm{Cs}$ & 0,0037 & $<0,00005$ & $<0,00005$ & 0,00007 & $<0,00005$ & $<0,00005$ & 0,00026 & $<0,00005$ & 0,000074 & 0,00026 & 0,0017 & 0,0017 \\
\hline I & 0,0060 & 0,0016 & 0,0011 & 0,0025 & 0,0011 & 0,0021 & 0,0045 & 0,0033 & 0,0019 & 0,0014 & $0, .0044$ & 0,0056 \\
\hline $\mathrm{Ba}$ & 0,021 & 0,021 & 0,014 & 0,02 & 0,015 & 0,012 & 0,011 & 0,069 & 0,027 & 0,02 & 0,17 & 0,18 \\
\hline $\mathrm{La}$ & $<0,00005$ & 0,00015 & 0,00011 & $<0,00005$ & 0,000081 & $<0,00005$ & $<0,00005$ & $<0,00005$ & 0,00013 & 0,00054 & 0,00008 & $<0,00005$ \\
\hline $\mathrm{Ce}$ & $<0,00005$ & 0,00029 & 0,00016 & $<0,00005$ & 0,000097 & $<0,00005$ & 0,000058 & $<0,00005$ & 0,00024 & 0,00097 & 0,00017 & 0,000072 \\
\hline $\mathrm{Nd}$ & $<0,00005$ & 0,000097 & 0,00012 & $<0,00005$ & 0,00009 & $<0,00005$ & $<0,00005$ & $<0,00005$ & 0,00012 & 0,00042 & 0,000055 & $<0,00005$ \\
\hline $\mathrm{U}$ & 0,019 & 0,0086 & 0,0015 & 0,0021 & 0,0012 & 0,0017 & $<0,00005$ & 0,0014 & 0,0012 & 0,0017 & 0,0059 & 0,0056 \\
\hline
\end{tabular}

Примечание: «<»-ниже предела обнаружения.

Note: «<»-below detection limit. 
держание $\mathrm{Sr}$ в «здоровых» водах, обратив при этом внимание на относительно высокое его значение в ряде неблагополучных в отношении эндемии рек (Сивачи, Уров, Газимур).

Необходимо отметить, что подземные воды по средней величине $\mathrm{Ca} / \mathrm{Sr}$ отношения характеризуются как благоприятные, за исключением пробы из с. Тайна. В то время как в поверхностных водах их соотношение составляет от 91 до 129 и находится в зоне риска использования поверхностных вод в качестве питьевых (табл. 3). Если предположить, что на момент установленного факта развития болезни поверхностная вода использовалась населением как источник питьевого водоснабжения, то обоснованно проявляется связь её существования с малыми значениями соотношения кальция и стронция.

Иные данные по Са и $\mathrm{Sr}$ опубликованы в недавней работе по этой же территории [38]. Согласно авторам, содержание Са в водах эндемических ра-

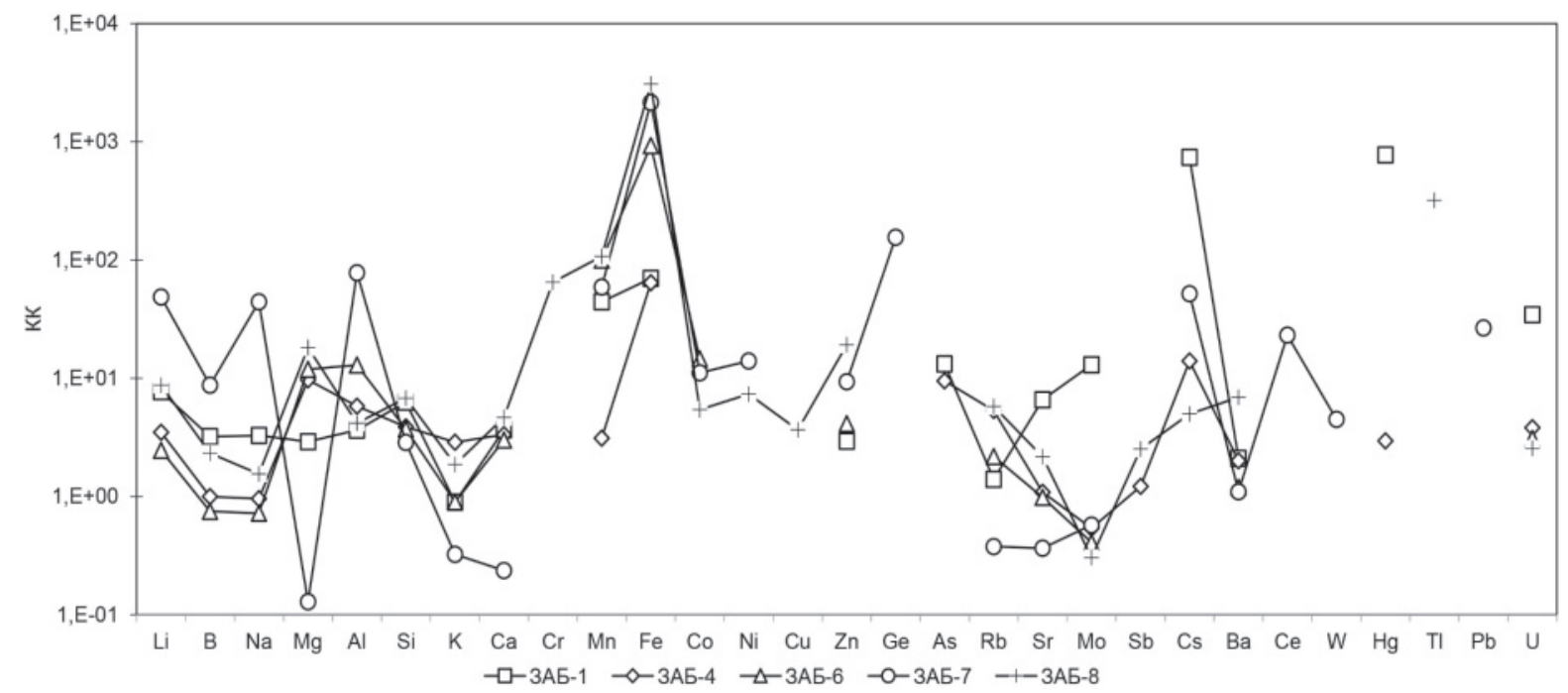

Pис. 2. Норлированные на средний состав байкальской воды спектры содержания химических элементов в подзелных водах: КК - коэффициент концентрации относительно среднего состава байкальской воды [36]

Fig. 2. Spectra of chemical elements in groundwater normalized by the average composition of Lake Baikal water: KK-concentration coefficient relative to the average composition of Lake Baikal water [36]

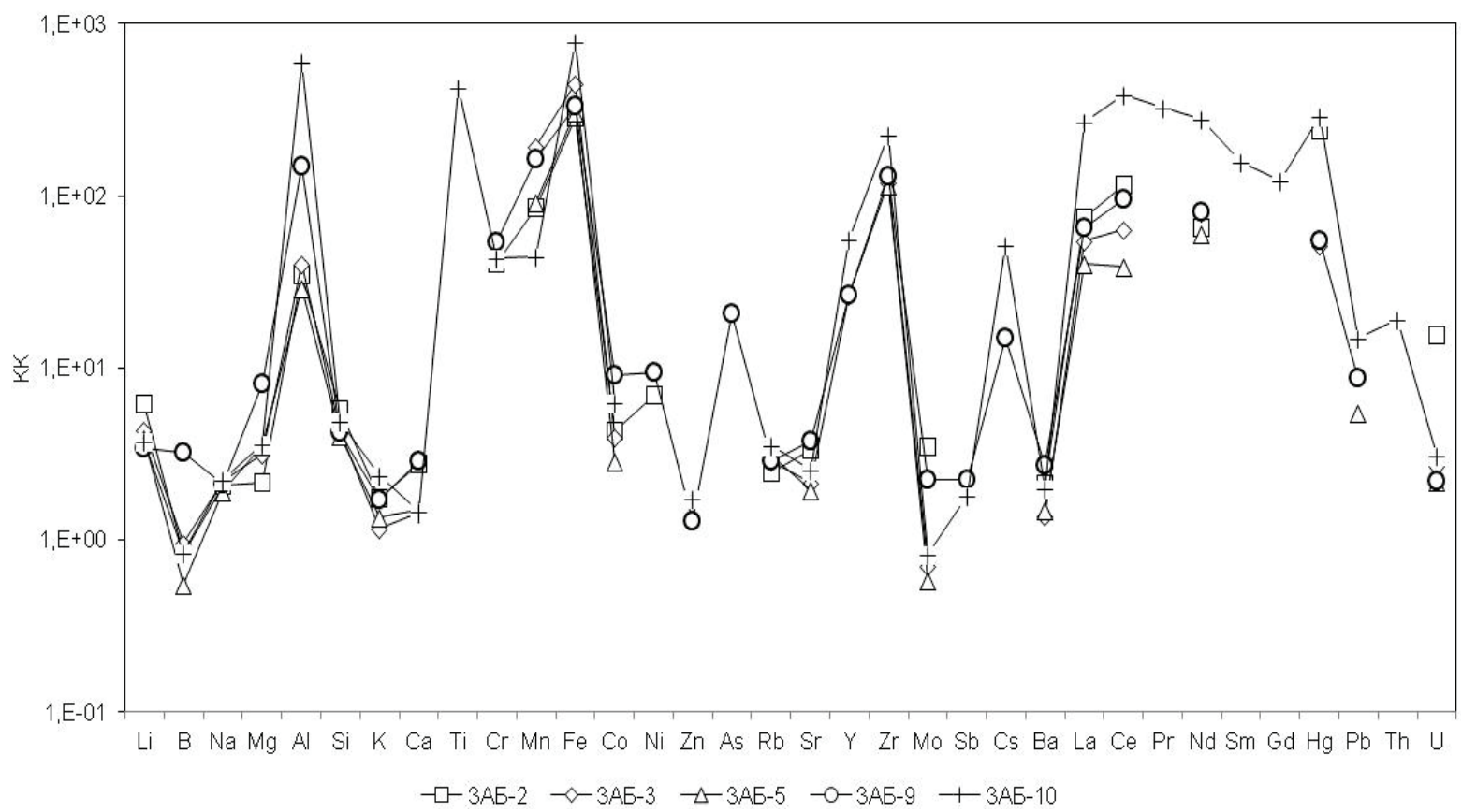

Рис. 3. Нормированные на средний состав байкальской воды спектры содержания хилических әлементов в поверхностных водах: 2) $К К$ - коэффициент кониентрации относительно среднего состава байкальской воды [36]

Fig. 3. Spectra of chemical elements in surface waters normalized by the average composition of Lake Baikal water: KK-concentration coefficient relative to the average composition of Lake Baikal water [36] 
йонов даже выше, чем в благополучных («контрольных») по заболеванию в населенных пунктах (средние концентрации 35,9 и 32,9 мг/дм ${ }^{3}$ при максимальных 156,8 и $108,2 \mathrm{мг} /$ дм $^{3}$, соответственно). Но первые отличаются заметно более высокими концентрациями $\mathrm{Sr}$, достигающими 2983 мкг/дм ${ }^{3}$ при максимуме в незатронутых болезнью местах 532 мкг/дм ${ }^{3}$ при этом средние соотношения $\mathrm{Ca} / \mathrm{Sr}$ равны 285 и 543 при наиболее часто встречаемых интервалах 50-300 и 100-400, соответственно. В почвах эндемических местностей это соотношение варьирует от 2 до 98 , а в районах без проявления уровской болезни - в пределах 11-256. Повышенное содержание $\mathrm{Sr}$ в почвах и растениях рассматривается авторами как фактор экологического риска.

Что касается высокого содержания $\mathrm{Sr}$ в почве в с. Солонцы, вызванного, как полагают авторы [38], влиянием флюоритового месторождения Сoлонечное, то для такого объяснения нет оснований. Месторождение удалено от села на 10 км и находится на левом борту долины ручья, тогда как село - на правом, к тому же правый борт долины пересекают боковые распадки с эрозионным врезом, через который вторичные геохимические ореолы месторождения распространяться не могли, не говоря уже об удаленности указанного источника Sr. В дополнение к этому, содержание $\mathrm{Sr}$ в штольневых водах Солонечного и расположенного несколько выше по ручью в том же рудном поле Брикачанского месторождения флюорита по данным нашего опробования в 2012 г. было 0,18 и $0,04 \mathrm{мг} /$ дм $^{3}$, что определенно свидетельствует об отсутствии повышенных концентраций $\mathrm{Sr}$ во флюоритовых рудах.

Полученные нами гидрогеохимические данные по питьевым водам с. Тайна, в котором уровской болезнью было поражено 30,4 \% жителей [28], показывают, что крайне низкое содержание Са в питьевой воде может служить достаточным индикатором неблагополучия территории по этому заболеванию с позиции биогеохимической гипотезы А.П. Виноградова без отягчающего влияния как $\mathrm{Sr}$, так и $\mathrm{P}$, несмотря на то, что вода не служит основным источником поступления Са в организм человека. Однако нельзя игнорировать наличие аномалий $\mathrm{P}$ в водах многих эндемичных местностей. Они связаны не только с пойменными луговоболотными ландшафтами, как это трактуется в работе [38]. По нашим данным $[14,15]$, аномалии $\mathrm{P}$ отмечены и вне пойм в родниковых водах из коренных пород, к примеру, в местах бывших сел Годымбой, Патрино и других местностях. При биологическом значении Р в образовании костной ткани его аномалии в почвах, водах и растениях не могут не учитываться. Недаром самим автором биогеохимической гипотезы приведены данные по содержанию $\mathrm{CaO}$ и $\mathrm{P}_{2} \mathrm{O}_{5}$ в сене различных территорий: в областях с остеопорозом животных в разных странах они в среднем соответственно равны (в \% ) 0,52 и 0,22 , по району уровской эндемии $-0,56$ и 0,48 , в «хорошем» сене из разных стран $-1,2$ и 0,52 . Отношения $\mathrm{CaO} / \mathrm{P}_{2} \mathrm{O}_{5}$ по этим данным соответственно составляют $2,36,1,17$ и 2,31, а пересчитанные на $\mathrm{Ca} / \mathrm{P}-3,85,1,9$ и $3,79 . \mathrm{K}$ этому надо добавить, что в статье В.С. Малининой [39] в том же сборнике, что и статья [27], как раз подчеркнуто нарушение Са-Р баланса в питании уровских больных в peзультате избытка $\mathrm{P}$.

\section{Заключение}

Таким образом, нами получены новые данные по содержанию 71 химического элемента, многие из которых ранее не изучались в этом эндемичном районе, в поверхностных и подземных водах, используемых местным населением для питьевого водоснабжения. По содержанию большинства изученных микроэлементов воды, за исключением источника Ямкун, являются слабоминерализованными и характеризуются как условно чистые.

Аномальные концентрации имеют только Мо $\left(15\right.$ мкг/дм $\left.{ }^{3}\right)$ и U $\left(0,019 \mathrm{мг} /\right.$ дм$\left.^{3}\right)$ в водном источнике в с. Калга, что может быть вызвано наличием соответствующей рудной минерализации в зоне влияния водозабора или формированием фильтрационного потока к нему. Это требует дополнительного изучения, тем более что он прилегает к известному урановорудному району Забайкалья.

Полученные гидрогеохимические данные по питьевым водам с. Тайна, в котором уровской болезнью было поражено 30,4 \% жителей, показывают, что крайне низкое содержание Са в питьевой воде может служить достаточным индикатором неблагополучия территории по этому заболеванию с позиции биогеохимической гипотезы А.П. Виноградова без отягчающего влияния как $\mathrm{Sr}$, так $\mathrm{P}$ и $\mathrm{Mn}$.

По содержанию Са $\left(3,8\right.$ мг/дм $\left.{ }^{3}\right)$ только привозная вода из с. Тайна относится к категории «больных», согласно А.П. Виноградову. В «здоровых» родниковых и речных водах по приведенным им данным концентрации Са находились в интервале 30-80 мг/дм ${ }^{3}$, тогда как в «больных» были менее $20 \mathrm{мг} /$ дм³ $^{3}$. Ca/Sr отношение, рекомендованное в качестве дополнительного критерия неблагополучия территории по уровской болезни при его значении менее 100 , в нашем исследовании обусловлено, прежде всего, низким содержанием Sr в воде.

Se в опробованных водах не обнаружен (менее $0,005 \mathrm{мг} /$ дм $\left.^{3}\right)$, что соответствует существующим оценкам территории как селенодефицитной и дальнейшее исследование этого компонента потребует использования методики его определения ниже 5 мкг/л.

Данные по содержанию I подтверждают его недостаток в питьевых водах, что может вызывать развитие тиреоидной патологии, на фоне которой может проявиться болезнь Кашина-Бека.

Научные исследования выполнены в рамках программы повышения конкурентоспособности ТПУ среди ведущих мировых исследовательских иентров 


\section{СПИСОК ЛИТЕРАТУРЫ}

1. Stone R. A medical mystery in middle China // Science. - 2009 _ V. 324. - P. 1378-1381.

2. Дамперов Н.И. Карта распространения уровской болезни // Уровская болезнь в Забайкалье. - Иркутск, 1934. - С. 15-23.

3. Allander E. Kashin-Beck disease. An analysis of research and public health activities based on a bibliography 1849-1992 // Scandinavian Journal of Rheumatology. - 1994. - V. 23. - P. 1-36.

4. Big bone disease: a multidisciplinary approach of Kashin-Beck disease in Tibet Autonomous Region (P.R. China) / Eds. F. Malaisse, F. Mathieu. - Gembloux: Les Presses Agronomiques de Gembloux, 2008. $-148 \mathrm{p}$.

5. Epidemiological support for a multifactorial aetiology of KashinBeck disease in Tibet / C. Suetens, R. Moreno-Reyes, C. Chasseur, F. Mathieu, F. Begaux, E. Haubruge, M.C. Durand, J. Neve, J. Vanderpas // International Orthopaedics. - 2001. - V. 25. P. $180-187$.

6. Geological characteristics and etiology research on Kashin-Beck Disease in China / Y. An, X. Jia, F. Li, J. He, S. Han, H. Zhang // Geology in China. - 2010. - V. 37. - P. 563-570.

7. Yao Y., Pei F., Kang P. Selenium, iodine, and the relation with Kashin-Beck Disease // Nutrition. - 2011. - V. 27. P. $1095-1100$

8. Recent advances in the research of an endemic osteochondropathy in China: Kashin-Beck disease / X. Guo, W. Ma, F. Zhang, F.-L. Ren, C.-J. Qu, M.J. Lammi // Osteoarthritis and Cartilage. - 2014. - V. 22. - P. 1774-1783.

9. Environmental water chemistry and possible correlation with Kaschin-Beck Disease (KBD) in northwestern Sichuan, China / Z. Shi, P. Pan, Y. Feng, Z. Kan, Z. Li, F. Wei // Environment International. - 2017. - V. 99. - P. 282-292.

10. Zinc: the Other Suspected Environmental Factor in Kashin-Beck Disease in Addition to Selenium / X. Wang, Y. Ning, L. Yang, F. Yu, X. Guo // Biological Trace Element Research. - 2017. V. $179 .-$ P. $178-184$.

11. Nutrients Other than Selenium Are Important for Promoting Children's Health in Kashin-Beck Disease Areas / Y. Ning, X. Wang, X. Guo, P. Zhang, P. Qu, F. Zhang, S. Wang, Y. Lei, M. Lammi // Biological Trace Element Research. - 2018. V. $183 .-$ P. $233-244$.

12. Selenium Content and/or T-2 Toxin Contamination of Cereals, Soil, and Children's Hair in Some Areas of Heilongjiang and Gansu Provinces, China / L. Sun, S. Cui, Q. Deng, H. Liu, Y. Cao, S. Wang, J. Yu // Biological Trace Element Research. - 2019. DOI: $10.1007 / \mathrm{s} 12011-018-1620-7$

13. Замана Л.В., Гладкая Н.М. Новые данные по геохимии природных вод района уровской эндемии в Сибири // Доклады Академии наук. - 1991. - Т. 321. - № 3. - С. 593-595.

14. Zamana L.V., Gladkaya N.M. Geochemical features of the natural waters in the Urov biogeochemical region // Geochemistry International. - 1993. - V. 30. - № 9. - P. 105-116.

15. Zamana L.V. Possible hydrogeochemical preconditions for Kashin-Beck disease in Transbaikalia // Chinese Geographical Science. - 1995. - V. 5. - P. 185-192.

16. Zamana L.V. Hydrogeochemistry in Kaschin-Beck Disease (KBD) areas of Transbaikalia, Russia // Geology in China. - 2010. V. 37. - P. 582-586.

17. Wang Z. A historic overview of research and control on KashinBeck Disease in China // Chinese Journal of Endemiology. 1999. - V. 18. - P. 161-163.

18. Levander 0.A. Selenium // Trace Elements in Human and Animal Nutrition / Ed. by W. Mertz. - London: Academic Press, 1986. P. 139-197.

19. Environmental selenium in the Kaschin-Beck disease area, Tibetan Plateau, China / B. Zhang, L. Yang, W. Wang, Y. Li, H. Li // Environmental Geochemistry and Health. - 2011. - V. 33. P. 495-501.
20. Selenium: A protective factor for Kaschin-Beck disease in QingTibet plateau / Z.-J. Zhao, Q. Li, P.-Z. Yang, H. Wang, L.-C. Kong, L.-H. Wang, L.-Y. Sun // Biological Trace Element Research. - 2013. - V. 153. - P. 1-4.

21. Constraint on selenium bioavailability caused by its geochemical behavior in typical Kaschin-Beck disease areas in Aba, Sichuan Province of China / Y. Lv, T. Yua, Z. Yang, W. Zhao, M. Zhang, Q. Wang // Science of the Total Environment. - 2014. - V. 493. P. 737-749.

22. Guo X., Ning Y., Wang X. Selenium and Kashin-Beck disease // Selenium: Chemistry, Analysis, Function and Effects (Food and Nutritional Components in Focus) / Ed. by V.R. Preedy. - Cambridge: Royal Society of Chemistry, 2015. - P. 552-571.

23. Trace Element Levels in Scalp Hair of School Children in Shigatse, Tibet, an Endemic Area for Kaschin-Beck Disease (KBD) / Y. Guo, H. Li, L. Yang, Y. Li, B. Wei, W. Wang, H. Gong, M. Guo, C. Nima, S. Zhao, J. Wang // Biological Trace Element Research. - 2017. - V. 180. - P. 15-22.

24. Distribution and translocation of selenium from soil to highland barley in the Tibetan Plateau Kashin-Beck disease area / J. Wang, H. Li, L. Yang, Y. Li, B. Wei, J. Yu, F. Feng // Environmental Geochemistry and Health. - 2017. - V. 39. - P. 221-229.

25. Du B., Zhou J., Zhou J. Selenium status of children in Kashin-Beck disease endemic areas in Shaanxi, China: assessment with mercury // Environmental Geochemistry and Health. - 2018. - V. 40. - P. 903-913.

26. Associations Between Selenium Content in Hair and Kashin-Beck Disease/Keshan Disease in Children in Northwestern China: a Prospective Cohort Study / H. Liu, F. Yu, W. Shao, D. Ding, Z. Yu, F. Chen, D. Geng, X. Tan, M.J. Lammi, X. Guo // Biological Trace Element Research. - 2018. - V. 184. - P. 16-23.

27. Виноградов А.П. 0 причинах происхождения уровской эндемии (геохимические исследования) // Труды Биогеохимической лаборатории. - М.: Изд-во АН СССР, 1949. - Т. 9. - С. 5-29.

28. К этиологии уровской (Кашина-Бека) болезни / А.В. Вощенко, В.Н. Чугаев, С.И. Вайстух, В.С. Бутко // Педиатрия: вопросы диагностики и лечения: тезисы докладов научно-практической конференции. - Чита, 1988. - С. 20-23.

29. Геохимические особенности среды и эндемические заболевания Забайкальского края / М.А. Солодухина, Л.А. Михайлова, С.Э. Лапа, Н.М. Бурлака // Забайкальский медицинский вестник. - 2015. - № 4. - С. 169-174.

30. Ковальский В.В. Новые направления и задачи биологической химии сельскохозяйственных животных в связи с изучением биогеохимических провинций // Материалы Юбилейной сессии, посвященной 40-й годовщине Великой Октябрьской социалистической революции (ВАСХНИЛ). - М.: Изд-во Минсельхоза СССР, 1958. - С. 579-619.

31. Алексенцева Н.Н. Эколого-геохимические особенности территории Юго-Восточного Забайкалья, эндемичной по болезни Кашина-Бека: автореф. дис. ... канд. геол.-мин. наук. - Минск, 1987. -20 c.

32. Геохимическая обстановка в очагах Кешанской болезни / А.В. Вощенко, В.Н. Чугаев, Л.И. Говорина, В.В. Красницкая // Экологические интоксикации: биохимия, фармакология, клиника: тезисы докладов Всероссийской научной конференции. - Чита, 1996. - С. 2-21.

33. Аникина JI.В., Никитина Л.П. Селен. Экология, патология, коррекция. - Чита: ИИЦ ЧГМА, 2002. - 400 c.

34. Кашин В.К. Биогеохимия йода в ландшафтах Забайкалья // Геохимия. - 1996. - № 5. - С. 463-471.

35. Основы гидрогеохимических поисков рудных месторождений / Б.А. Колотов, С.Р. Крайнов, В.З. Рубейкин и др. - М.: Недра, 1983. -199 c.

36. Ветров В.А., Кузнецова А.И., Склярова О.А. Базовые уровни химических элементов в воде озера Байкал // География и природные ресурсы. - 2013. - № 3. - С. 41-51. 
37. Крайнов С.Р., Швец В.М. Геохимия подземных вод хозяйственно-питьевого назначения. - М.: Недра, 1987. - 237 с.

38. Биогеохимия кальция и стронция в ландшафтах Восточного Забайкалья / В.В. Ермаков, У.А. Гуляева, С.Ф. Тютиков, Т.Г. Кузьмина, В.А. Сафонов // Геохимия. - 2017. - № 12. C. $1115-1127$.
39. Малинина В.С. Некоторые данные о составе пищевых продуктов в районе распространения уровской эндемии // Труды Биогеохимической лаборатории. - М.: Изд-во АН СССР, 1949. T. 9. - C. 55-64.

\section{Информация об авторах}

Замана Л.В., кандидат геолого-минералогических наук, ведущий научный сотрудник лаборатории геоэкологии и гидрогеохимии Института природных ресурсов, экологии и криологии СО РАН.

Рихванов Л.П., доктор геолого-минералогических наук, профессор отделения геологии Инженерной школы природных ресурсов Национального исследовательского Томского политехнического университета.

Соктоев Б.P., кандидат геолого-минералогических наук, старший преподаватель отделения геологии Инженерной школы природных ресурсов Национального исследовательского Томского политехнического университета.

Барановская H.B., доктор биологических наук, профессор отделения геологии Инженерной школы природных ресурсов Национального исследовательского Томского политехнического университета.

Эпова E.C., кандидат геолого-минералогических наук, научный сотрудник лаборатории геохимии и рудогенеза Института природных ресурсов, экологии и криологии СО РАН.

Солодухина M.A., кандидат географических наук, научный сотрудник лаборатории геохимии и рудогенеза Института природных ресурсов, экологии и криологии СО РАН.

Михайлова Л.A., кандидат медицинских наук, заведующая кафедрой гигиены Читинской государственной медицинской академии.

Копылова Ю.Г., кандидат геолого-минералогических наук, начальник научно-образовательного центра «Вода» Инженерной школы природных ресурсов Национального исследовательского Томского политехнического университета.

Хващевская $A . A .$, кандидат геолого-минералогических наук, заведующая проблемной научно-исследовательской лабораторией гидрогеохимии Инженерной школы природных ресурсов Национального исследовательского Томского политехнического университета. 
UDC 556.114:616.71(571.55)

\section{NEW DATA ON CHEMICAL COMPOSITION OF NATURAL WATERS IN THE AREA OF DISTRIBUTION OF UROV (KASCHIN-BECK) DISEASE (TRANSBAIKAL REGION)}

Leonid V. Zamana',

I.v.zamana@mail.ru

Leonid P. Rikhvanov²,

rikhvanov@tpu.ru

Bulat R. Soktoev²,

bulatsoktoev@tpu.ru

Natalia V. Baranovskaya², nata@tpu.ru

\section{Ekaterina S. Epova',}

apikur1@ya.ru

\section{Mariya A. Solodukhina',}

mabn@ya.ru

Larisa A. Mikhailova ${ }^{3}$,

mihailova-la@mail.ru

Yulia G. Kopylova²,

kyg@tpu.ru

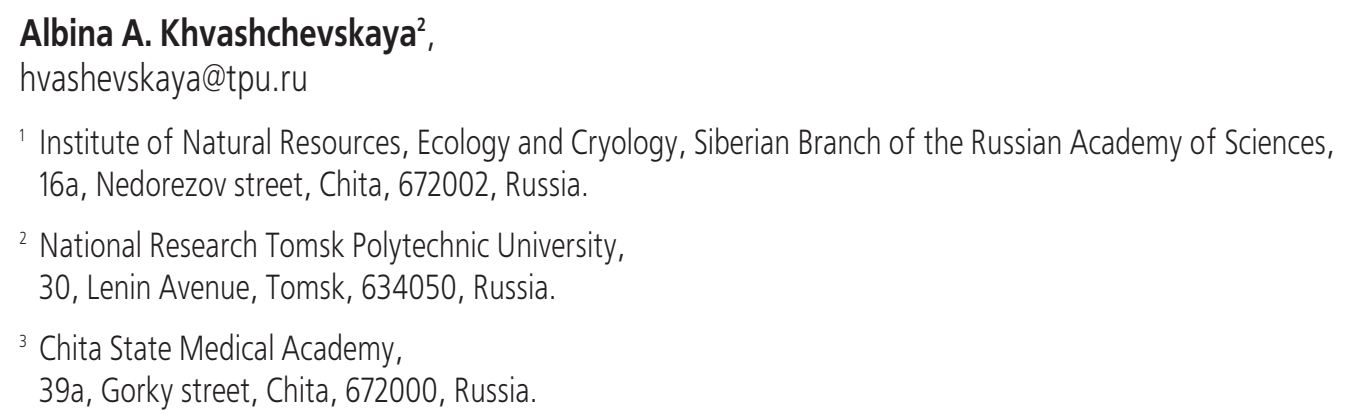

The relevance of the research. The Kaschin-Beck disease, or Urov disease, has been known for over 160 years, but the real reason, that causes the disease development, has not been still identified. For the moment there are more than 20 theories and hypotheses explaining the reasons for its occurrence, the leading one is the biogeochemical, first proposed by A.P. Vinogradov. According to this theory, the Kaschin-Beck disease is related to the influence of the environment in the form of lack or excess of a chemical element or compounds. In this regard, it is relevant to study the chemical composition of natural components in the manifestation area of this disease. The main aim of the research is to evaluate the chemical composition of natural waters used for drinking water supply in the manifestation area of the Kaschin-Beck disease in Transbaikal region.

Objects: underground and surface waters.

Methods. Hydrogeochemical, chemical composition of water samples was detected with the use of inductively coupled plasma mass spectrometry.

Results. The content of 71 chemical elements, including those not previously considered for this area, was studied in natural waters. We have established that waters used for drinking water supply are characterized by low content of calcium, which may be an indicator of trouble in areas with this disease without aggravating effects of either strontium or phosphorus and manganese. The levels of selenium and iodine in the studied waters are below the optimum value for drinking usage. This fact agrees well with the literature data for China, where the natural components (water, soil, vegetation) in the areas of the Kaschin-Beck disease distribution are depleted in iodine. In this case, the lack of iodine can cause the development of endemic goitre, against which the Urov disease manifests itself brighter.

\section{Key words:}

Urov disease, Kaschin-Beck disease, hydrogeochemistry, chemical composition, underground and surface waters, calcium, selenium, iodine.

The research was carried out within the Program of enhancement of TPU competitiveness among the leading worlds research centers. 


\section{REFERENCES}

1. Stone R. A medical mystery in middle China. Science, 2009, vol. 324, pp. 1378-1381.

2. Damperov N.I. Karta rasprostraneniya urovskoy bolezni [Map of Urov disease distribution]. Urovskaya bolezn $v$ Zabaykale [Urov disease in Transbaikalia]. Irkutsk, 1934. pp. 15-23.

3. Allander E. Kashin-Beck disease. An analysis of research and public health activities based on a bibliography 1849-1992. Scandinavian Journal of Rheumatology, 1994, vol. 23, pp. 1-36.

4. Big bone disease: a multidisciplinary approach of Kashin-Beck disease in Tibet Autonomous Region (P.R. China). Eds. F. Malaisse, F. Mathieu. Gembloux, Les Presses Agronomiques de Gembloux, $2008.148 \mathrm{p}$

5. Suetens C., Moreno-Reyes R., Chasseur C., Mathieu F., Begaux F., Haubruge E., Durand M.C., Neve J., Vanderpas J. Epidemiological support for a multifactorial aetiology of KashinBeck disease in Tibet. International Orthopaedics, 2001, vol. 25, pp. 180-187.

6. An Y., Jia X., Li F., He J., Han S., Zhang H. Geological characteristics and etiology research on Kashin-Beck Disease in China. Geology in China, 2010, vol. 37, pp. 563-570.

7. Yao Y., Pei F., Kang P. Selenium, iodine, and the relation with Kashin-Beck Disease. Nutrition, 2011, vol. 27, pp. 1095-1100.

8. Guo X., Ma W., Zhang F., Ren F.-L., Qu C.-J., Lammi M.J. Recent advances in the research of an endemic osteochondropathy in China: Kashin-Beck disease. Osteoarthritis and Cartilage, 2014, vol. 22, pp. 1774-1783.

9. Shi Z., Pan P., Feng Y., Kan Z., Li Z., Wei F. Environmental water chemistry and possible correlation with Kaschin-Beck Disease (KBD) in northwestern Sichuan, China. Environment International, 2017, vol. 99, pp. 282-292.

10. Wang X., Ning Y., Yang L., Yu F., Guo X. Zinc: the Other Suspected Environmental Factor in Kashin-Beck Disease in Addition to Selenium. Biological Trace Element Research, 2017, vol. 179 , pp. 178-184.

11. Ning Y., Wang X., Guo X., Zhang P., Qu P., Zhang F., Wang S., Lei Y., Lammi M. Nutrients Other than Selenium Are Important for Promoting Children's Health in Kashin-Beck Disease Areas. Biological Trace Element Research, 2018, vol. 183, pp. 233-244.

12. Sun L., Cui S., Deng Q., Liu H., Cao Y., Wang S., Yu J. Selenium Content and/or T-2 Toxin Contamination of Cereals, Soil, and Children's Hair in Some Areas of Heilongjiang and Gansu Provinces, China. Biological Trace Element Research, 2019. DOI: 10.1007/s12011-018-1620-7

13. Zamana L.V., Gladkaya N.M. New data on the chemistry of natural waters in the region of endemic bone disease (Kashin-Beck disease) in Siberia. Doklady Akademii nauk, 1991, vol. 321 (3), pp. 593-595. In Rus.

14. Zamana L.V., Gladkaya N.M. Geochemical features of the natural waters in the Urov biogeochemical region. Geochemistry International, 1993, vol. 30 (9), pp. 105-116.

15. Zamana L.V. Possible hydrogeochemical preconditions for Kashin-Beck disease in Transbaikalia. Chinese Geographical Science, 1995, vol. 5, pp. 185-192.

16. Zamana L.V. Hydrogeochemistry in Kaschin-Beck Disease (KBD) areas of Transbaikalia, Russia. Geology in China, 2010, vol. 37, pp. $582-586$.

17. Wang Z. A historic overview of research and control on KashinBeck Disease in China. Chinese Journal of Endemiology, 1999, vol. 18, pp. 161-163.

18. Levander 0.A. Selenium. In Trace Elements in Human and Animal Nutrition. Ed. by W. Mertz. London, Academic Press, 1986. pp. 139-197.

19. Zhang B., Yang L., Wang W., Li Y., Li H. Environmental selenium in the Kaschin-Beck disease area, Tibetan Plateau, China. Environmental Geochemistry and Health, 2011, vol. 33, pp. $495-501$.
20. Zhao Z.-J., Li Q., Yang P.-Z., Wang H., Kong L.-C., Wang L.-H., Sun L.-Y. Selenium: A protective factor for Kaschin-Beck disease in Qing-Tibet plateau. Biological Trace Element Research, 2013, vol. 153, pp. 1-4.

21. Lv Y., Yua T., Yang Z., Zhao W., Zhang M., Wang Q. Constraint on selenium bioavailability caused by its geochemical behavior in typical Kaschin-Beck disease areas in Aba, Sichuan Province of China. Science of the Total Environment, 2014, vol. 493, pp. 737-749.

22. Guo X., Ning Y., Wang X. Selenium and Kashin-Beck disease. In Selenium: Chemistry, Analysis, Function and Effects (Food and Nutritional Components in Focus). Ed. by V.R. Preedy. Cambridge, Royal Society of Chemistry, 2015. pp. 552-571.

23. Guo Y., Li H., Yang L., Li Y., Wei B., Wang W., Gong H., Guo M., Nima C., Zhao S., Wang J. Trace Element Levels in Scalp Hair of School Children in Shigatse, Tibet, an Endemic Area for Kaschin-Beck Disease (KBD). Biological Trace Element Research, 2017, vol. 180, pp. 15-22.

24. Wang J., Li H., Yang L., Li Y., Wei B., Yu J., Feng F. Distribution and translocation of selenium from soil to highland barley in the Tibetan Plateau Kashin-Beck disease area. Environmental Geochemistry and Health, 2017, vol. 39, pp. 221-229.

25. Du B., Zhou J., Zhou J. Selenium status of children in Kashin-Beck disease endemic areas in Shaanxi, China: assessment with mercury. Environmental Geochemistry and Health, 2018, vol. 40, pp. 903-913.

26. Liu H., Yu F., Shao W., Ding D., Yu Z., Chen F., Geng D., Tan X., Lammi M.J., Guo X. Associations Between Selenium Content in Hair and Kashin-Beck Disease/Keshan Disease in Children in Northwestern China: a Prospective Cohort Study. Biological Trace Element Research, 2018, vol. 184, pp. 16-23.

27. Vinogradov A.P. 0 prichinakh proiskhozhdeniya urovskoy endemii (geokhimicheskie issledovaniva) [About the reasons of origin of Urov endemic disease (geochemical research)]. Trudy Biogeokhimicheskoy laboratorii [Proceedings of the biogeochemical laboratory]. Moscow, AN SSSR Publ., 1949. Vol. 9, pp. 5-29.

28. Voschenko A.V., Chugaev V.N., Vaystukh S.I., Butko V.S. K etiologii urovskoy (Kashina-Beka) bolezni [To etiology of Urov (Kashin-Beck) disease]. Pediatriya: voprosy diagnostiki i lecheniya: tezisy dokladou nauchno-prakticheskoy konferentsii [Pediatrics: diagnostic and treatment issues: proc. of scientific conference]. Chita, 1988. pp. 20-23.

29. Solodukhina M.A., Mikhailova L.A., Lapa S.E., Burlaka N.M. Geochemical features of the environment and endemic disease Trans-baikal territory. Transbaikalian Medical Bulletin, 2015, no. 4, pp. 169-174. In Rus.

30. Kovalskiy V.V. Novye napravleniya i zadachi biologicheskoy khimii selskokhozyaystvennykh zhivotnykh v svyazi s izucheniem biogeokhimicheskikh provintsiy [New directions and issues of biological chemistry of farm animals in connection with the study of biogeochemical provinces]. Materialy Yubileinoy sessii, posvyashchennoy 40-y godoushchine Velikoy Oktyabrskoy sotsialisticheskoy revolyutsii (VASKHNIL) [Proc. of the Jubilee session devoted to the $40^{\text {th }}$ anniversary of the great October socialist revolution (VASKHNIL)]. Moscow, Ministry of agriculture of the USSR Publ. house, 1958. pp. 579-619.

31. Aleksentseva N.N. Ekologo-geokhimicheskie osobennosti territorii Yugo-Vostochnogo Zabaykalya, endemichnoy po bolezni KashinaBeka. Avtoreferat Dis. Kand. nauk [Ecological and geochemical peculiarities of the South-Eastern Transbaikalia territory endemic for Kaschin-Beck disease. Cand. Diss. Abstract]. Minsk, $1987.20 \mathrm{p}$.

32. Voschenko A.V., Chugaev V.N., Govorina L.I., Krasnitskaya V.V. Geokhimicheskaya obstanovka v ochagakh Keshanskoy bolezni [Geochemical conditions in the focuses of Keshan disease]. Ekologicheskie intoksikatsii: biokhimiya, farmakologiya, klinika: tezisy dokladou Vserossiyskoy nauchnoy konferentsii [En- 
vironmental intoxication: biochemistry, pharmacology, clinic: abstracts of the all-Russian scientific conference]. Chita, 1996. pp. 20-21.

33. Anikina L.V., Nikitina L.P. Selen. Ekologiya, patologiya, korrek tsiya [Selenium. Ecology, pathology, correction]. Chita, IIC CSMA, 2002. $400 \mathrm{p}$.

34. Kashin V.K. Biogeochemistry of iodine in the Transbaikalia landscapes. Geokhimiya, 1996, no. 5, pp. 463-471. In Rus.

35. Kolotov B.A., Kraynov S.R., Rubeykin V.Z. Osnovy gidrogeokhimicheskikh poiskov rudnykh mestorozhdeniy [Fundamentals of hydrogeochemical exploration for mineral deposits]. Moscow, $\mathrm{Ne}^{-}$ dra Publ., 1983. 199 p.

36. Vetrov V.A., Kuznetsova A.I., Sklyarova 0.A. Baseline levels of chemical elements in the water of Lake Baikal. Geography and $\mathrm{Na}$ tural Resources, 2013, vol. 34, no. 3, pp. 228-238.
37. Kraynov S.R., Shvets V.M. Geokhimiya podzemnykh vod khozyaystvenno-pitevogo naznacheniya [Geochemistry of groundwater for domestic and drinking purposes]. Moscow, Nedra Publ., 1987. $237 \mathrm{p}$.

38. Ermakov V.V., Gulyaeva U.A., Tyutikov S.F., Kuzmina T.G., Safonov V.A. Biogeochemistry of calcium and strontium in the landscapes of eastern Transbaikalia. Geochemistry, 2017, no. 12, pp. 1115-1127. In Rus.

39. Malinina V.S. Nekotorye dannye o sostave pischevykh produktov $\mathrm{v}$ rayone rasprostraneniya urovskoy endemii [Some data on the composition of foods in the distribution area of Urov endemia]. Trudy Biogeokhimicheskoy laboratorii [Proc. of the biogeochemical laboratory]. Moscow, AN SSSR Publ., 1949. Vol. 9, pp. 55-64.

Received: 26 April 2018.

\section{Information about the authors}

Leonid V. Zamana, Cand. Sc., leading research scientist, Institute of Natural Resources, Ecology and Cryology.

Leonid P. Rikhvanov, Dr. Sc., professor, National Research Tomsk Polytechnic University.

Bulat R. Soktoev, Cand. Sc., assistant professor, National Research Tomsk Polytechnic University.

Natalia V. Baranovskaya, Dr. Sc., professor, National Research Tomsk Polytechnic University.

Ekaterina S. Epova, Cand. Sc., research scientist, Institute of Natural Resources, Ecology and Cryology.

Mariya A. Solodukhina, Cand. Sc., research scientist, Institute of Natural Resources, Ecology and Cryology.

Larisa A. Mikhailova, Cand. Sc., head of the department, Chita State Medical Academy.

Yulia G. Kopylova, Cand. Sc., director of the center, National Research Tomsk Polytechnic University.

Albina A. Khvashchevskaya, Cand. Sc., head of research laboratory, National Research Tomsk Polytechnic University. 